\title{
The 5th International Conference on Gold Science, Technology and its Applications
}

\author{
University of Heidelberg, Germany Sunday 26 - Wednesday 29 July 2009 \\ 1st call for papers
}

\begin{abstract}
-000 Venue
With its glorious natural setting, a wonderful castle, historic old town and a beautiful river set in the midst of rolling hills, Heidelberg is regarded as one of the most attractive cities in Germany. It is also a progressive city of international importance in the fields of science, research and business. Not only is Germany's oldest university based in Heidelberg (the venue for the conference), but so are a number of outstanding research institutions and industrial companies. It is a truly wonderful setting for GOLD 2009 and we look forward to welcoming you to see for yourself next year!
\end{abstract}

\section{-000 Key dates \\ Call for papers \\ 1 May 2008}

Online abstract submission opens 1 September 2008

Deadline for abstract submission 15 January 2009

Notification of acceptance 2 April 2009

Final programme announced 15 April 2009

Conference

26-29 July 2009

\section{- 00 Students}

Special student rates for conference attendance will be announced on the conference website in due course.

\section{- Call for papers}

Abstracts for proposed oral papers or posters (maximum 1 page A4 single spaced) should be submitted via the conference website at www.gold2009.org where details of the full scope of the conference will be found. Submissions focused on end applications are particularly encouraged.
Gold science and technology is undergoing an exciting period of research and there is increasing commercial interest in practical applications. We are seeing the discovery of new reactions catalysed by gold... innovative uses of gold nanoparticles... fresh perspectives in gold chemistry... and novel materials science and gold metallurgy. Important new applications for gold in the field of green chemistry and medicine are emerging from laboratories around the world. Following the success of previous conferences, World Gold Council and the University of Heidelberg are pleased to announce the 1st Call for Papers for GOLD 2009. This conference will cover all aspects of the science, technology and applications of gold under the principal themes of:

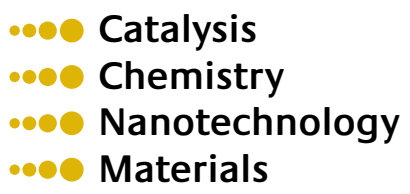

This is a unique, multidsciplinary event, that offers opportunities not afforded by many other conferences. Scientists and technologists in academia and industry have praised previous conferences in this series where they were able to meet, present and discuss the latest advances with colleagues from their own field and at the same time interact with experts from parallel areas of interest. Whilst the programme for each of these themes will be organised through separate technical committees a coherent approach to the overall conference programme is planned. An internationally respected group of keynote speakers covering the key topic areas will be announced shortly.
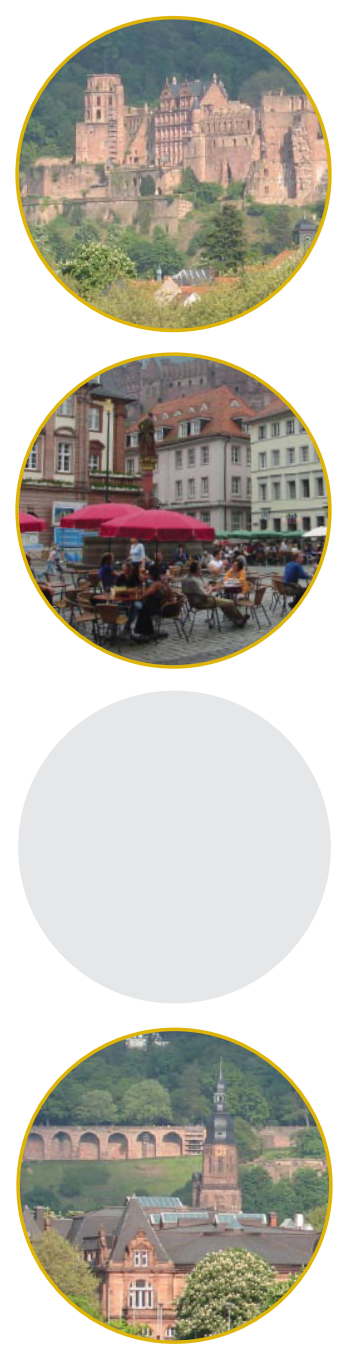

- Sponsors

Major sponsors of GOLD 2009 include

\section{-BASF \\ The Chemical Company}

WORLD GOLD COUNCIL

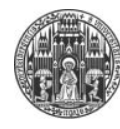

The University of Heidelberg

For further information on sponsorship opportunities please contact World Gold Council email: industry@gold.org

\section{Heraeus}

W. C. Heraeus $\mathrm{GmbH}$ 